\title{
Correction to: Assessment of Groundwater Potential in the Kalahandi District of Odisha (India) Using Remote Sensing, Geographic Information System and Analytical Hierarchy Process
}

\author{
T. Goitsemang ${ }^{1}$ - D. M. Das ${ }^{1} \cdot$ S. K. Raul ${ }^{1}$ (D) C. R. Subudhi ${ }^{1} \cdot$ B. Panigrahi ${ }^{1}$
}

Published online: 20 November 2020

(C) Indian Society of Remote Sensing 2020

\section{Correction to: Journal of the Indian Society of Remote Sensing}

https://doi.org/10.1007/s12524-020-01188-3

Unfortunately, the given name and family name of the first author T. Goitsemang were incorrectly published in the original publication. The correct given name and family name should read as ' $\mathrm{T}$ ' and 'Goitsemang', respectively.

The original article can be found online at https:// doi.org/10.1007/s12524-020-01188-3.

S. K. Raul

sanjaykraul@gmail.com

1 Department of Soil and Water Conservation Engineering, College of Agricultural Engineering and Technology, Odisha University of Agriculture and Technology,

Bhubaneswar 751003, India 